Provided for non-commercial research and education use. Not for reproduction, distribution or commercial use.

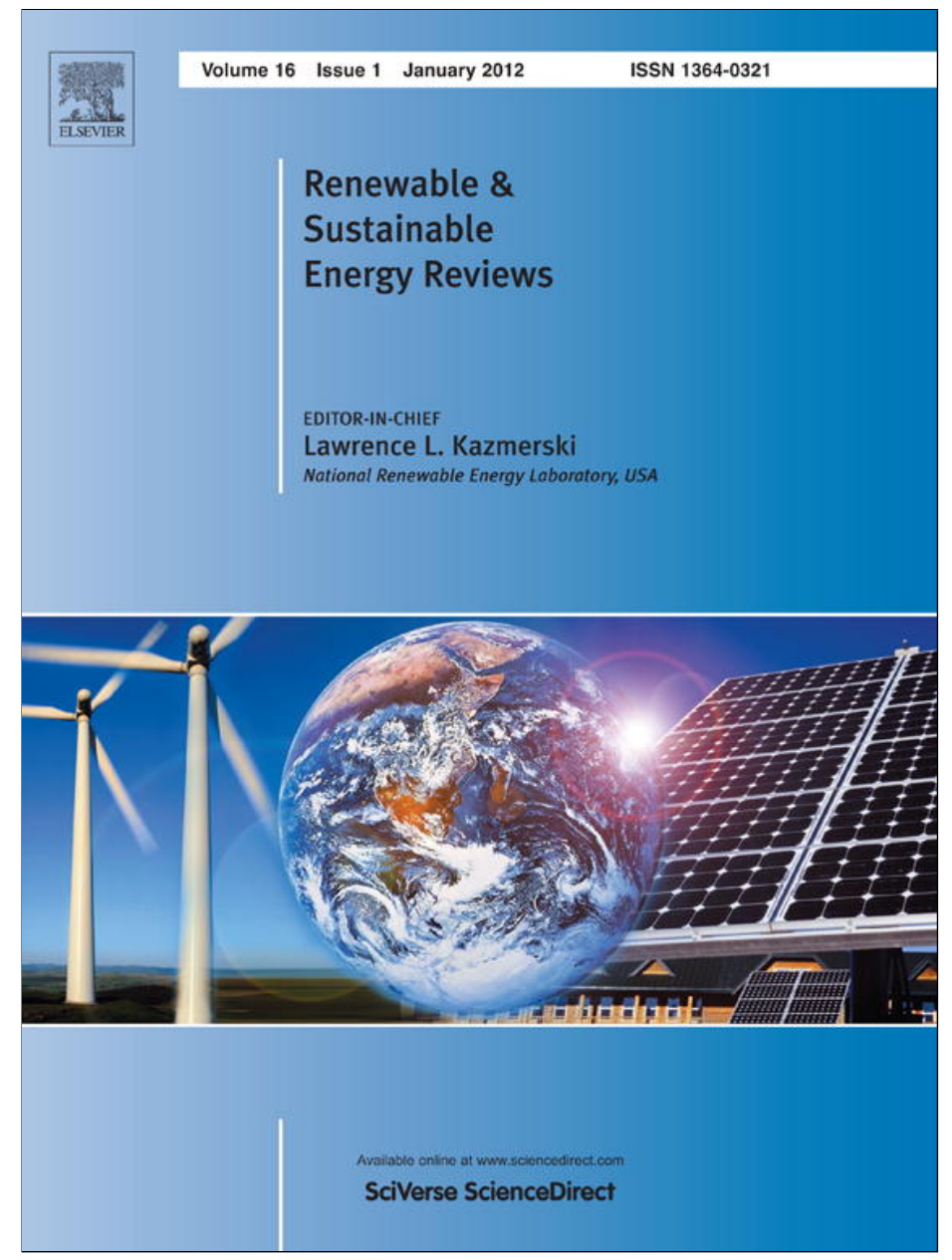

(This is a sample cover image for this issue. The actual cover is not yet available at this time.)

This article appeared in a journal published by Elsevier. The attached copy is furnished to the author for internal non-commercial research and education use, including for instruction at the authors institution and sharing with colleagues.

Other uses, including reproduction and distribution, or selling or licensing copies, or posting to personal, institutional or third party websites are prohibited.

In most cases authors are permitted to post their version of the article (e.g. in Word or Tex form) to their personal website or institutional repository. Authors requiring further information regarding Elsevier's archiving and manuscript policies are encouraged to visit:

http://www.elsevier.com/copyright 


\title{
The challenges of determining the employment effects of renewable energy
}

\author{
Rosebud Jasmine Lambert*, Patrícia Pereira Silva \\ Faculty of Economics, University of Coimbra, Av. Dias da Silva 165, 3004-512 Coimbra, Portugal
}

\section{A R T I C L E I N F O}

\section{Article history:}

Received 4 December 2011

Received in revised form

23 March 2012

Accepted 31 March 2012

\section{Keywords:}

Employment

Renewable energy

Job creation

\begin{abstract}
A B S T R A C T
The benefits of promoting renewable energy are regularly claimed to be energy security, climate change mitigation and job creation. While the first two benefits are generally accepted, the impact of renewable energy on employment is still disputed. This paper presents a discussion of the various factors that influence the analysis of renewable energy and its impact on employment. The advantages and disadvantages of input-output methods and analysis methods are discussed as well as the issues surrounding the measurement of job creation. A critical evaluation of the literature reveals factors that should be considered when completing a study about renewable energy and employment: labour intensity of renewables; cost increases and availability of investments; counting job losses; job quality and skills, model assumptions and sources of information. Analytical studies using extensive surveys were found to be more appropriate for regional studies while input-output methods were better suited to national and international studies.
\end{abstract}

(c) 2012 Elsevier Ltd. All rights reserved.

\section{Contents}

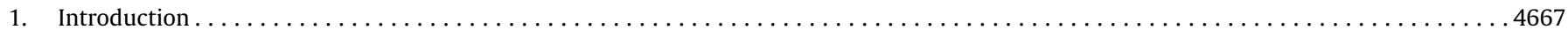



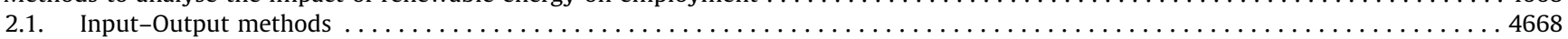

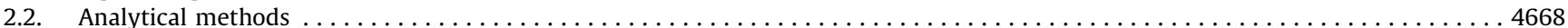

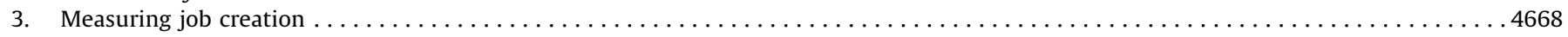

4. Factors that affect job estimates . . . . . . . . . . . 4670

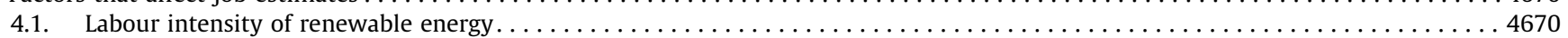

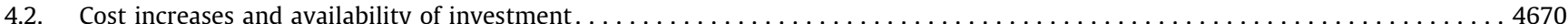



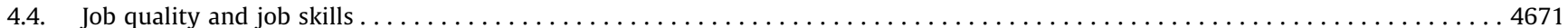

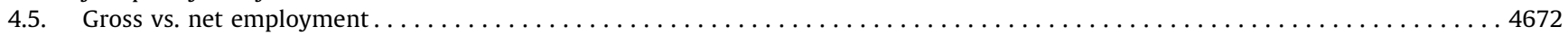

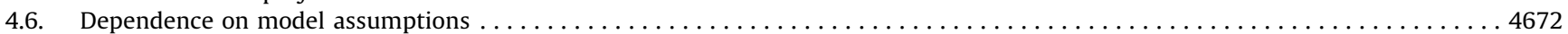

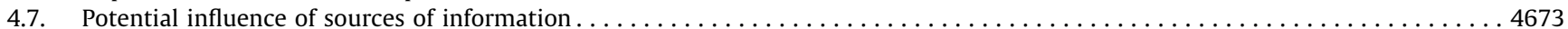

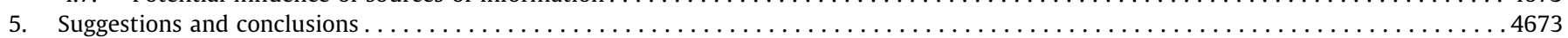



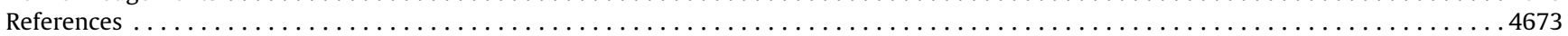

\section{Introduction}

Renewable energy is playing an increasing role in energy mixes around the world, including Europe, which is aiming for a target of $20 \%$ renewable energy by 2020 [1]. The benefits of renewable energy are widely accepted to include a decrease in

\footnotetext{
* Corresponding author. Tel.: +351916 415 559; fax: +351 239790514.

E-mail address: rosebud.lambert@gmail.com (R.J. Lambert).
}

greenhouse gas emissions and an improvement in energy security. In many cases job creation is also touted as a benefit but this claim stands on an uncertain footing.

While studies often present renewable energy as a boost to the economy through the generation of large job growth [2-4] there are often overly optimistic or simplistic assumptions that lead to these results. In some cases reasonable assumptions are made but selective reporting of results can lead to a false impression of job creation.

This paper does not attempt to provide a complete list or review of studies examining the impact of renewable energy on 
employment, but rather presents a summary of the issues that are often ignored when discussing the impact of renewable energy on employment.

In reviewing the literature it can be seen that some countries have become the focus of studies and reports about renewable energy and employment. In Europe, Germany and Spain have routinely been referenced due to an increasing contribution from renewable energy sources, in part due to the targets adopted to meet the European 2020 renewable energy target.

Germany's support for renewable energy has generated a number of studies, many of which are critical of the impact of renewables on the German economy [5-8]. Spanish studies have ranged from region-specific $[9,10]$ and technology-specific $[4,11]$ to a discussion of the wider economic impact [12].

Outside of Europe the United States' push for "green jobs" and a "green economy" has sparked debate about the actual impact of promoting renewable energy and other green jobs with arguments for [13-15] and against [16,17].

Following this introduction, this paper will present the most commonly used methods for analysing the impact of renewable energy on employment. This is followed by a discussion of how to measure job creation and then a discussion of important factors related to renewable energy and employment. Finally some conclusions and suggestions are made to address the issues highlighted in this report.

\section{Methods to analyse the impact of renewable energy on employment}

Studies analysing the impact of renewable energy on employment can be broadly categorised into two categories: InputOutput (I-O) methods and analytical methods, both with their own distinct advantages and disadvantages.

\subsection{Input-Output methods}

I-O methods offer the ability to model impacts of a sector on all the other sectors of an economy and are typically used for determining the economic impacts of a particular investment or activity. Using the I-O method it is also possible to analyse the employment impacts across the economy by increasing or reducing demand in a particular sector. Such examples include international or national estimates of employment $[5,11,18]$. A coefficient (also known as a multiplier) is used to describe the relationship between output, employment and income of one sector on other sectors of the economy.

Input-Output methods can calculate a number of different effects:

i. Direct effects-due to demand for goods and services in sectors of economy directly impacted by an activity. E.g. investing in a windfarm, or constructing a new biomass plant.

ii. Indirect effects - the impact that the activity has on productive sectors not directly impacted. E.g. the impact on the steel industry by building a new wind turbine.

iii. Induced effects-related to the expansion of private expenditure on goods and services.

In this way the number of direct jobs and indirect jobs can be calculated. This is in contrast to analytical methods which can only determine direct employment. I-O methods typically use comparison of different scenarios to determine the total impact on employment.

A significant limitation of the I-O method is the dependence on the coefficients used. These coefficients are static and do not always account for technological improvements, import substitution, changing consumption or relative price variations over time [19].

As discussed in Caldés et al. [11] homogeneity of sectors is also assumed, implying that consumption of goods and services and use of production is considered equal among different activities in the same sector. I-O methods also assume that there is no limit to the amount that a particular sector can produce.

Another disadvantage of I-O studies is the time lag between data collection and publication. For example Caldés et al. [11] used the most recent official input-output data available for a study of Spain with data from 2000 only being published in 2007. While this data is useful for determining historical impacts it is not a current snapshot of the economy, decreasing the accuracy of forecasts produced with this data.

Input-output data is usually only available on a national level, making it difficult to use this data for regional or provincial studies. Madlener and Koller [20] attempted to regionalise Austrian I-O tables to determine the impact of promoting biomass in Austria by estimating the amount of national product produced in their region of interest. Usually an analytical method based on job ratios and surveys is used for this type of study.

Some studies (e.g. [6]) have attempted to address the limitations of the input-output method by computing marginal affects, with the addition of other models, rather than relying on averaged affects. Hybrid methods combining I-O methods and extensive surveys have also been used, such as in the case of Lehr et al. [5].

\subsection{Analytical methods}

Analytical methods are commonly used for regional or provincial studies where the input-output method cannot easily be applied. The method is usually reliant on extensive surveys $[4,9]$.

While the analytical method may not be able to determine indirect jobs (only direct jobs), it can be a more transparent model, easily understood by other authors and able to have sensitivity evaluated.

Blanco and Rodrigues [4] highlight the limitations of using analytical methods. When surveys are used the subject of the survey needs to be properly identified with the whole population or a representative sample used for the survey. The questions in the survey need to avoid unbiased answers. When an official register is used, the reliability, accuracy and comprehensiveness of the employment data need to be considered. As noted in Satresa et al. [9] the accuracy of data is related to the objective of the agents involved. For example industrial associations are more likely to have current employment information than energy agencies, where the accuracy of employment data is secondary to other information.

An example of an extensive employment survey is the 2010 National Solar Jobs Census [21] undertaken by The Solar Foundation in the U.S. This census of solar businesses in the U.S. provides a snapshot of current employment in the solar industry. This type of survey can be an important foundation on which to build accurate projections of employment.

\section{Measuring job creation}

Input-output and analytical methods provide the framework for determining the number of jobs created, but as the body of literature concerning renewable energy and employment grows it has become increasingly obvious that there is no consensus on how best to measure job creation, especially for particular technologies. 
A review of the literature will find numerous ways of measuring jobs created: Jobs per annual MW installed, jobs per cumulative MW installed, manufacturing jobs per MW, person-year per MW, one-year jobs among others. Usually either of two forms is used: jobs per MW installed and person-year per MW installed. This difference is usually an attempt to give an indication of which stage the jobs are created. Typically jobs per MW installed is used to indicate the number of permanent jobs created in the operation and maintenance phase, while person-year per MW is used for temporary jobs in the construction phase.

Jobs in person-years per MW can be converted to jobs per MW by dividing by the life of the system. For example a value of 30 person-years per MW installed in the manufacturing stage, becomes 1 job per MW installed over a life time of 30 years. While this enables job ratios in different forms to be compared it gives little information about when the jobs are created. In this example the jobs are not evenly distributed at the lifetime of the system but are most likely concentrated in the initial phases.

There is also disagreement about how to account for the location and temporal nature of jobs. Sastresa et al. [9] gives the example of a German study by Lehr et al. [5] where installers are added to the operation and maintenance job ratio to differentiate between local jobs and jobs that may be created in a distant manufacturing plant. Other studies such as EPRI [22] add jobs to the installation stage to distinguish between temporary and permanent employment.

Denmark is often used as an example of how job ratios can be misleading when there is lack of clarity over whether jobs are local or have an export component, as discussed by Dalton and Lewis [23]. Denmark has a large wind turbine manufacturing sector (high jobs rate) with most of the components exported (low local deployment). This falsely inflates the job per MW ratio. Dalton and Lewis [23] also note a lack of clarity between cumulative or non-cumulative installed figures in some studies.

Sastresa et al. [9] attempted to provide a solution to addressing the local and export content of jobs and temporal nature of jobs in their study of the local impact of renewable energy in a province of Spain. Sastresa et al. [9] conducted an extensive survey or renewable energy companies and related parties to determine the number of direct jobs that existed in the province of Aragon.

The authors considered that renewable energy projects could be grouped into three categories, (rather than the traditional two of operation and maintenance, and installation):

1. Technological development-more likely to be a foreign job, stable and very highly specialised.

2. Installation/uninstallation-more likely to be local, temporary, highly specialised.

3. Operation and maintenance-local, stable and medium specialisation.

This grouping allowed a job ratio to be determined for each of the three categories, making it clear how many jobs were created at each phase of the life cycle of the renewable energy project. Based on the results of the extensive survey Sastresa et al. [9] determined job ratios for different renewable energy technologies such as wind, solar thermal and photovoltaics.

The job ratio results of Sastresa et al. [9], while specific to the province of Aragon in Spain, present an interesting relationship between cumulative installed renewable energy capacity and the employment ratio over time (see Fig. 1). As can be seen in Fig. 1 as cumulative installed power increased the employment ratio decreased (with the exception of a slight rise the year 2000, when the Plan for the Promotion of Renewable Energy in Spain was introduced) becoming more stable in recent years.



Fig. 1. Evolution of employment ratio over time in Aragon, Spain. Source: Sastresa et al. [9].

Table 1

Varying job ratios for wind energy. Gathered from [4].

\begin{tabular}{ll}
\hline Country & Job ratio (direct jobs/MW installed) \\
\hline Belgium & 6.97 \\
Denmark & 5.44 \\
Austria & 0.76 \\
Czech Republic & 0.86 \\
Spain & 1.35 \\
Germany & 1.71 \\
France & 2.44 \\
\hline
\end{tabular}

These results provide evidence that while the promotion of renewable energy causes peaks in the generation of local jobs through temporary installation and construction jobs, as these jobs come to an end the employment ratio stabilises as operation and maintenance jobs take over. Notably estimated job ratios varied widely between renewable technologies. The calculated total job ratio for wind energy was 0.86 jobs/MW, solar thermal 43 jobs/MW and photovoltaics 38 jobs/MW [9]. This demonstrates that job ratios from one technology cannot simply be applied to another.

Job ratios are often used to justify claims that specific forms of renewable energy technology can create a certain amount of jobs. This must be done with care however as there is a large range of job ratios for each technology. Table 1 highlights the danger of using job ratios from other studies or locations by comparing job ratios for wind energy in different countries. While all these job ratios were determined using the same method it is not possible to determine a common value that could be applied to all countries.

While analytical methods generally only determine direct jobs there can be some ambiguity surrounding what is a direct and indirect job. Generally direct jobs refer to manufacturing only but in some cases installation is also included [23]. This confusion can be avoided by using guidance from professional organisations where possible. For example EWEA provides a definition of what is a direct and indirect job for wind energy [24]. In any case the definition of what is considered a direct or indirect job should be clearly defined in individual studies.

Gülen [25] suggests that using jobs per MW to compare job creation between renewable energy technologies and conventional energy generation is flawed. Gülen [25] suggests an alternative job ratio-jobs per dollar invested; to more accurately compare the economic efficiency of generation technologies. This method was illustrated by Huntington [26] who produced a table comparing jobs per MW and jobs per dollar invested (shown in part in Table 2). 
Table 2

Comparison of Jobs/MW and Jobs/\$ for different generation technologies. Based on Huntington [26].

\begin{tabular}{|c|c|c|c|c|c|c|}
\hline & $\begin{array}{l}(1) \\
\text { Jobs/MWa }\end{array}$ & $\begin{array}{l}(2) \\
\text { Jobs/GWh }\end{array}$ & $\begin{array}{l}\text { Jobs/SMillion based } \\
\text { on Metcalf costs }\end{array}$ & $\begin{array}{l}\text { (4) } \\
\text { Jobs/SMillion based on } \\
\text { EIA estimate cost }\end{array}$ & $\begin{array}{l}(5) \\
\text { Metcalf levelised } \\
\text { cost } \mathbf{S / k W h}\end{array}$ & $\begin{array}{l}\text { (6) } \\
\text { EIA levelised cost } \\
\text { for } 2016 \$ / \mathbf{k W h}\end{array}$ \\
\hline Photovoltaics (low) & 7.41 & 0.85 & 2.79 & 4.01 & 0.303 & 0.2107 \\
\hline Photovoltaics & 10.56 & 1.21 & 3.98 & 5.72 & 0.303 & 0.2107 \\
\hline Wind (low) & 0.71 & 0.08 & 1.44 & 0.84 & 0.056 & 0.097 \\
\hline Wind & 2.79 & 0.32 & 5.66 & 3.28 & 0.056 & 0.097 \\
\hline Biomass (low) & 0.78 & 0.09 & 1.58 & 0.79 & 0.056 & 0.1125 \\
\hline Biomass & 2.84 & 0.32 & 5.75 & 2.88 & 0.056 & 0.1125 \\
\hline Coal & 1.01 & 0.12 & 3.27 & 1.22 & 0.035 & 0.0948 \\
\hline Natural gas & 0.95 & 0.11 & 1.80 & 1.64 & 0.060 & 0.0661 \\
\hline
\end{tabular}

Explanation:

Column (1): Jobs per MW adjusted for capacity factor and averaged over a year. Based on averages determined from a review of U.S. and European studies (Source: [27]). Column (2): Column (1) $\times 10^{3} \div 8760$

Column (3): Jobs per million dollars (2009 dollars) based on Metcalf [28] cost estimates as used by Huntington [26]. Column (2) $\div$ Column (5).

Column (4): Jobs per million dollars (2009 dollars) based on EIA Annual Energy Outlook 2011 total system levelised cost in 2016. Column (2) $\div$ Column (6)

Column (5): Levelised cost of generation from Metcalf [28] as used by Huntington [26]. Adjusted from 2004 to 2009 dollars.

Column (6): Levelised cost of generation for plants entering service in 2016 based on EIA Annual Energy Outlook 2011 [29]. In 2009 dollars.

The table presents values for several renewable energy technologies as well as the conventional technologies of coal and natural gas. Note that Photovoltaics (low), Wind (low), Biomass (low) are the lowest job ratio estimates based on a review by Kammen et al. [27]. The levelised cost used by Huntington [26] (column 5) to calculate jobs per million dollars is taken from a report by Metcalf [28]. All dollar values in Table 2 are in 2009 \$US, Metcalf [28] values were adjusted from 2004 values based on annual averages of the U.S. Consumer Price Index.

Note that decreasing the levelised cost of renewables will improve the number of jobs created per dollar invested (assuming the jobs per MW ratio remains the same). To highlight the impact levelised cost can have on the jobs per dollar invested ratio, an additional column (column 4 ) has been added, using the predicted 2016 levelised cost of the EIA Annual Energy Outlook 2011 [29] (shown in column 6).

The values taken from Huntington [26] demonstrate that there may be little difference in job creation between renewable and conventional energy generation, contradictory to what is often assumed in studies, although this conclusion is highly dependent on the jobs per MW ratio used. However it can also be seen that as the levelised cost of renewable energy generation changes there is also a corresponding change in the jobs per dollar invested ratio. If the levelised cost of renewables decreases in the future, renewables will become more economically attractive in comparison to conventional technologies.

\section{Factors that affect job estimates}

This section will discuss various factors that affect estimations of job creation and job estimates. Some of these factors are only briefly mentioned in reports but consideration of all these issues is important when making an overall claim about renewable energy and employment.

Michaels and Murphy [16] and Gülen [25] both provide interesting (non-peer reviewed) critiques with a particular focus on the United States. A 2009 study of the Spanish renewable energy industry [12] supports the sentiment of Michaels and Murphy [16] and Gülen [25], urging caution in implementing a Spanish/EU style green jobs agenda in the U.S. due to an overall negative impact on employment.

A similar argument has also been used for the UK. In his 2011 report focused on the UK Governments CO2 targets Hughes [30] also claims that the promotion of renewables creating growth and jobs is an "illusion", arguing that based on the total economic impact of promoting renewables in the UK that there will not be any job growth.

Bowen [31] also highlighted that macroeconomic impacts of renewables must be considered but adds that the impact of renewables will vary depending on the structure of the economy. For example the arguments against promoting 'green' jobs in the U.S. may not be valid to apply to a developing country.

All of these authors (and others) cite a number of factors that must be considered, but are often ignored, when discussing the impact promoting renewable energy. The various factors have been separated in this section but are inextricably interconnected. All of these factors must be considered together when making an evaluation of the impact of renewable energy on employment.

\subsection{Labour intensity of renewable energy}

The labour intensity of renewable energy has been discussed by both Frondel et al. [7] and Michaels and Murphy [16]. As noted by del Rio and Burguillo [32] studies generally show that renewable energy is more labour intensive than conventional energy. For example a given amount of workers in the renewable energy sector will produce less energy than the same amount of workers in the conventional energy sector, i.e. renewable energy is less efficient per worker than conventional forms of generation.

In a review of several U.S. studies Michaels and Murphy [16] concluded that in the studies reviewed all assumed that the higher labour intensity of renewable energy compared to conventional forms of generation is an advantage. However this claim encourages using technology that decreases the output of the economy. Thus promoting renewable energy technologies over other forms of generation is counterproductive to net job creation and economic growth by driving down productivity through increased costs [16]. Frondel et al. [7] agrees with this sentiment with the support of several studies including Hillebrand et al. [6] and Hughes [30].

Given this potential negative impact of renewable energy the higher labour intensity of renewable energy technologies should not automatically be considered a benefit in studies.

\subsection{Cost increases and availability of investment}

Along with direct job losses in the conventional energy industry (discussed in 4.3), promotion of renewable energy could also cause job losses through the drain on economic activity 
caused by higher electricity prices [7,16]. Lesser [17] dubs the ignorance of higher electricity prices that result from supporting renewable energy as "free-lunch economics", as the full impact of supporting renewables, particularly through subsidies and mandates, is often ignored in job studies.

As discussed by Lesser [17], Michaels and Murphy [16] and Frondel et al. [7] higher electricity prices lead to a loss of purchasing power for private consumers. With less money to spend consumers decrease consumption of goods and services leading to job losses in other industries.

Increasing investment in renewable energy systems means that less money is available to be invested in other sectors. In effect the total amount of investment available from industry may be reduced, with the resultant loss of purchasing power and investment capital also reducing employment in other sectors $[30,33]$.

\subsection{Counting job losses and treatment of the labour market}

An estimation of the impact of implementing renewable energy is incomplete without consideration of resulting job losses, both job losses due to the replacement of conventional sources of generation and job losses resulting from increased energy prices and reduced consumption of other goods and services. Studies warning of the impact of crowding out conventional energy sources include Pfaffenberger et al. [8] and Frondel et al. [7], while studies warning of increasing energy costs include Lehr et al. [5] and Hillebrand et al. [6].

The Employ-RES study, which found that promotion of renewable energy will create a net increase in jobs in Europe, acknowledged that the total effect of renewable energy on employment was strongly dependent on energy cost increases, with higher costs dampening the employment increase [18]. Lehr et al. [5] share this sentiment in their report about renewable energy and employment in Germany.

In a study of Aragon in Spain, Sastresa et al. [9] concluded that, at least historically, job losses in the conventional energy sector cannot be solely blamed on the uptake of renewable energy as their results showing the trend between employment between the two sectors would initially suggest (see Fig. 2). The authors concluded after studying the electricity mix of Aragon that the slowing down of employment in the conventional energy sector was due to factors such as the replacement of thermoelectric plants with less employment intensive alternatives such as cogeneration or combined cycle. While this situation may not be representative of all cases this is an important point to consider before placing blame of decreasing employment in the

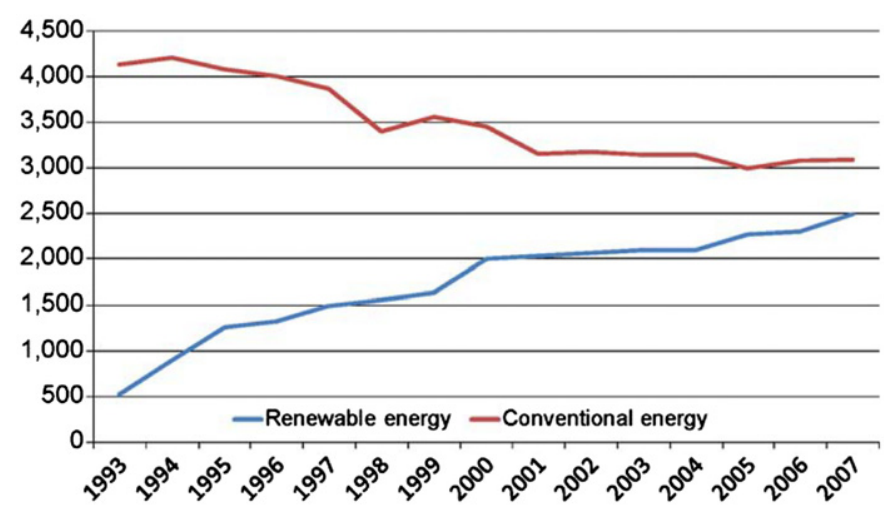

Fig. 2. Evolution of employment in the conventional energy sector and in the renewable energy sector.

Source: [9]. conventional energy sector on the promotion of renewable energy technology.

Job 'shifting' from one economic sector to others must also be considered. The workers that are employed in the renewable energy industry may not come from the pool of unemployed, a point vigorously highlighted by Michaels and Murphy [16] and Gülen [25]. At least some of the skilled workers will move from another job, resulting in no net increase in employment. In addition input-output analyses assume an unlimited pool of unemployed [16] an unrealistic assumption that could cause overestimation of the creation of employment.

\subsection{Job quality and job skills}

While job ratios can be used to describe the amount of jobs that are created, describing the type of jobs created is much more difficult. Usually temporary jobs are considered less skilled than more stable jobs.

A novel approach to describe the quality of jobs created was introduced by Sastresa et al. [9]. To give an indication of the local component of a job and the skill level required Satresa et al. [9] introduced a Quality Factor for each technology, with the Quality Factor ranging between 1 and -1 . A Quality Factor (QF) of 1 would indicate a very specialised, stable and local job while a factor of -1 indicates the opposite. The QF was calculated using adjustment factors for territoriality, temporal nature of job and specialisation of job (called 'indicators' by the authors) but the exact adjustment factors are not described in detail by the authors.

The results of Sastresa et al. [9] indicate a positive QF for wind energy in Aragon and a negative quality factor for solar thermal and photovoltaics, indicating that wind energy generated higher quality jobs than other technologies (see Table 3).

While the method presented by Sastresa et al. [9] provides a unique way to reflect the temporal nature, territoriality and specialisation of jobs created, it is reliant on subjective 'adjustment factors' that are not defined in the paper. Without these adjustment factors it is not possible for other authors to make a clear judgement on the use of the Quality Factor and to determine the sensitivity of results to the adjustment factors chosen. For example Sastresa et al. [9] implies that more specialised jobs in the technological development stage (such as $R \& D$, and which are more likely to be foreign than local, see Section 3) are higher quality than operation and maintenance jobs. While specialised jobs may attract a higher income it seems a somewhat judgemental argument to assume that operation and maintenance jobs that could provide local jobs to people with low specialisation of skills are 'lower quality' and therefore less attractive to create compared to 'high quality' jobs.

Del Rio and Burguillo [32] disagree with the implication of Satresa et al. [9] in their study of the impact of renewables on local sustainability. In the case of renewable energy placed in a rural location, jobs with low skill requirements are likely to provide more employment benefits to the local community than high-skilled jobs, due to the likely low skills of rural workers [32]. The greater the need for low skilled workers, the greater the

Table 3

Quality factor results for renewable energy in Aragon Spain [9].

\begin{tabular}{lc}
\hline & Quality factor \\
\hline Wind & 0.61 \\
Solar thermal & -0.90 \\
Photovoltaics & -0.54 \\
\hline
\end{tabular}


positive impact on the community, with job opportunities for the unemployed.

\subsection{Gross vs. net employment}

The way job statistics and study results are presented can lead to an overly optimistic impression. For this reason it is important that the difference between gross and net employment effects is clarified. Gross effects include only the positive impact on employment while net effects include both positive and negative impacts, leading to an overall impact on employment. In some studies it is unclear if gross or net values are being quoted.

For example the EmployRES study [18] which examined employment effects of renewable energy in Europe included analysis of many economic effects leading to an estimation of a total net increase of 115,000 to 417,000 jobs by 2020 . The total gross employment was determined to be 2.3 million to 2.8 million jobs (where the upper estimation was based on an aggressive policy scenario). While the distinction between these values was made clear in the report and policy summary, this report was quoted in a communication to the European parliament: "by 2020 [renewable energy] could employ a further 3 million" [34]. While this statement is strictly true, quoting the upper limit of gross employment values leads to an overly optimistic impression of how many jobs are actually being created in the economy.

\subsection{Dependence on model assumptions}

The outcome of macroeconomic and input-output studies is heavily dependent on the assumptions made. While this may seem an obvious statement in some cases without aggressive or optimistic scenarios there is negligible net job growth.

Such is the case with the EmployRES study [18] of the impact of renewable energy on employment in the EU27. This study compared the results of several models and considered many of the impacts discussed previously, including:

- Changes in demand of the conventional energy sector,

- Energy price changes,

- Changes in industry investment,

- Increase in investment of renewable, and decreasing investment in the conventional energy sector.

Two scenarios were considered in the study: continuing with current renewable energy policy in a Business As Usual (BAU) scenario and a hypothetical scenario with stronger support for renewables known as the Accelerated Deployment Policies scenario (ADP). Three export projections were also made: pessimistic export (PE) which is a hypothetical scenario used as a reference where all European renewable policy is abandoned, moderate export (ME) and optimistic export (OE).

The EmployRES report concluded that with the BAU scenario assuming a moderate export projection there is a net increase of $115,000-201,000$ jobs in 2020 (and 396,00-417,000 jobs in ADP-
ME scenario) compared to the hypothetical no policy scenario. These values must be used with caution. Given that current European policy promotes a $20 \%$ renewable energy target it is unlikely that that the reference no policy scenario will occur, meaning that actual net increase in jobs will be less than quoted. It is interesting to note that even in the no policy scenario there was still growth in the renewable energy sector.

As acknowledged by the authors of the study this growth on employment was dependent on the competitiveness of European exports. To achieve a more significant increase in employment a hypothetical and more aggressive renewable energy policy was needed.

A similar result was found by Lehr et al. [5]. Without strong international expansion renewable energy was not able to deliver a significant employment benefit to Germany. However despite this the model still predicted a small net increase in employment in Germany in 2020.

Due to Germany's strong renewable energy policy there have been several studies aiming to determine the effect on the German economy including Lehr et al. [5], Frondel et al. [7], Pffanberger et al. [8] and Hillebrand et al. [6]. The Hillebrand et al. [6] study modelled the economic impact of German renewable energy policy, including feed-in tariffs, using an input-output economic model with additional models to model the marginal (rather than average) effects. Two scenarios were computed: a reference scenario where the share of renewable energy does not change and a second scenario where the share of renewables is expanded.

The Hillebrand et al. [6] model included:

- The effects of changes in investment in renewable and convention energy sectors,

- Investment needed to upgrade the electricity grid,

- Modification of the power plant fleet. Instead of combined cycle gas turbines for base load, more flexible gas turbines will be needed to cope with the variability of power,

- Increase in cost of electricity,

- Effect on foreign imports.

Hillebrand et al. [6] concluded that the overall impact of promoting renewable energy results is a slightly negative impact on employment. The study observed two clear impacts on employment:

1. An expansive effect caused by investment in renewable energy systems increasing production and employment in related sectors.

2. A contractive effect caused by an increase in electricity prices. This leads to reduced demand and investment in other sectors.

Initially the expansive effect dominates but in later years the effect of increased costs and reduction in new renewable energy facilities counteracts the expansive effect, resulting in a small net loss of jobs compared to the reference scenario.

Table 4

Comparison of renewable energy job forecasts for the U.S. 2020-2030.

\begin{tabular}{|c|c|c|c|}
\hline Jobs forecast & Assumptions & Methodology & Source \\
\hline $274,000(2025)$ & $25 \%$ of electricity from renewables by 2025 & $\begin{array}{l}\text { Direct, indirect and induced jobs related to project development, manufacturing, } \\
\text { construction and operation }\end{array}$ & {$[35]$} \\
\hline $802,000(2028)$ & $40 \%$ of electricity from renewables & $\begin{array}{l}\text { Direct and indirect jobs. Jobs estimated using coefficient for jobs/MWh installed } \\
\text { capacity for different technologies (not given in report) }\end{array}$ & [13] \\
\hline $\begin{array}{l}900,000(2020)- \\
1.15 \text { mil (2030) }\end{array}$ & $\begin{array}{l}\text { Aggressive renewable energy and energy } \\
\text { efficiency scenario }\end{array}$ & $\begin{array}{l}\text { Net employment effect, direct and indirect jobs. Input/output method based on } \\
\text { projected costs of deploying renewables }\end{array}$ & {$[14]$} \\
\hline
\end{tabular}


This scenario is specific to Germany but shows the importance of comparing to a relevant reference scenario and considering the net effect, rather than just the gross effect.

The impact of model assumptions can be seen by comparing different forecasts of new renewable energy jobs in the U.S. for the period 2020-2030. Table 4 highlights the variety of job estimates in the literature and the effect of different assumptions. Table 4 demonstrates that it is necessary to use caution if selecting the results of a particular study.

Note that in Table 4 the estimate of the Management Information Services [14] report is significantly higher. The job forecast of this report is for renewable energy industry jobs but it is important to note that this job estimate takes into account the potential impact of energy efficiency. The savings from implementing energy efficiency reduce the negative impact of the higher costs of renewable energy. Based on a detailed inputoutput analysis the report concludes that with an aggressive scenario for renewable energy and energy efficiency there can be a net creation of jobs, reduction in emissions and net costs of near zero by 2030 . The approach taken by this model suggests that energy efficiency may be an effective way of softening the economic costs of renewable energy.

\subsection{Potential influence of sources of information}

The review of the literature conducted for this paper revealed that care must be taken when using the results of studies, particularly for non-peer reviewed studies which have the potential to exhibit some bias (intended or not). For example the DG Energy and Transport study [18] paints a positive outlook for renewable energy in Europe despite this being dependent on an optimistic scenario. This study, commissioned by the European Commission, was then used as support for the European renewable energy target in the European Parliament. It is possible that the intended use of the study may have influenced the way results were presented.

Some reports do not discuss the total impact on the economy. For example the Navigant consulting report [35] prepared the RES (Renewable Electricity Standard) Alliance for Jobs states that 274,000 more jobs will exist in the U.S. renewable energy industry if a $25 \%$ renewable energy target was implemented. There is no discussion of net employment effects. By only focussing on jobs in the renewable energy industry it is hardly surprising to find that a mandate of $25 \%$ renewables would create more renewable energy jobs.

In contrast both Gülen [25] and Michaels and Murphy [16], both reports with a U.S. focus, conclude that renewable energy will cost jobs. Michael and Murphy present valid criticisms in their report but they only review four U.S. reports. Gülen [25] presents an aggressive criticism of job creation of renewable energy without considering what costs may be avoided by using renewable energy technologies.

In addition to considering the source of results, the suitability of referenced results should also be taken into account. One such example of the poor use of study results is Romero et al. [36], published in 2012, which stated that an energy mix of $12 \%$ renewable energy would generate 500,000 jobs. This data (a forecast for 2010) came from the TERES II study commissioned by the European Union and was published in 1998 [37]. Is it still relevant to reference this report given the changes in European policy, the weakening of the European economy and the age of the data?

In summary it is important to consider who commissioned and performed the study, what the intended use is and what sources of information were used to form their results and conclusions. This is particularly important when using results from non-peer reviewed reports.

\section{Suggestions and conclusions}

This study has found a wide variety in the quality and transparency of studies related to renewable energy and employment. It is clear that care needs to be taken when presenting the results of studies, defining clearly what the gross and net effects are and what a direct and indirect job is.

There is no single method that gives the highest quality results, although comparison of different model results within the one study, as was done in the Employ-RES study [18], can help to support the results, although in this case care needs to be taken when using the results due to the reference scenario used.

Studies that blindly quote employment benefits from other studies may be giving a false impression of the potential benefit in their region. It is clear that job ratios vary widely between technologies, regions, countries and study methodologies. Jobs ratios should not be used as evidence of job creation unless using a study specific to the region and technology under discussion.

It is the opinion of the authors that analytical studies determining the number of direct jobs created through the promotion of renewable energy should rely on first hand information collected through an extensive survey. Job ratios from other studies or regions should not be used. It is important to consider the sources of information and motivation for the study, particularly for non-peer reviewed studies.

When conducting a study of the impact of renewable energy on employment on a national or international scale input-output methods are more appropriate as they can model the impacts across the whole economy, considering the impact on both direct and indirect jobs. However when evaluating and using the results of these studies it is important that the assumptions of the model are considered. Gross and net impacts should be determined. It is apparent that in studies that present a positive job growth due to renewable energy the result is usually reliant on strong policy support and optimistic export conditions.

Just as there is no single method for determining the impact of renewable on employment there is no single clear result about whether renewable energy positively or negatively effects employment. Promotion of renewable energy in one region of a country may produce a net increase in jobs (such as in [9]), slightly reduce job on a national scale [6] or bring a slight net benefit on an international scale [18]. The policy framework, dominant industries and energy mix of the area being studied play a pivotal role on the potential of renewable energy to impact employment.

It is also important to acknowledge that even if a study demonstrates that renewable energy reduces net employment, there may be other potential benefits such as a reduction in $\mathrm{CO}_{2}$ emissions or an increase in energy security. In summary renewable energy should be not encouraged solely because of a perceived benefit to employment, nor should it be rejected without consideration of other potential benefits.

\section{Acknowledgements}

The second author would like to acknowledge that this work has been partially supported by FCT under project grant PEst-C/ EEI/UI0308/2011.

\section{References}

[1] European Parliament, Directive 2009/28/EC of the European Parliament and of the Council of 23 April 2009 on the promotion of the use of energy from renewable sources and amending and subsequently repealing Directives 2001/77/EC and 2003/30/EC. L140/16. Brussels; 2009. 
[2] UNEP, towards a green economy: pathways to sustainable development and poverty eradication; 2011. Last accessed 21st March 2012, 〈http://www. unep.org/greeneconomy/>.

[3] WWF, Low Carbon jobs for Europe: current opportunities and future prospects; 2009. Last accessed 21st March 2012, 〈http://assets.panda.org/ downloads/low_carbon_jobs_final.pdf $>$.

[4] Blanco M, Rodrigues G. Direct employment in the wind energy sector: an EU study. Energy Policy 2009;37:2847-57.

[5] Lehr U, Nitsch J, Kratzat M, Lutz C, Edler D. Renewable energy and employment in Germany. Energy Policy 2008;36:108-17.

[6] Hillebrand B, Butterman H, Behringer J, Bleuel M. The expansion of renewable energies and employment effects in Germany. Energy Policy 2006;34: 3484-94.

[7] Frondel M, Ritter N, Schmidt C, Vance C. Economic impacts from the promotion of renewable energy technologies: the German experience. Energy Policy 2010;38:4048-56.

[8] Pfaffenberger W, Jahn K, Djourdjin M. Case study paper: renewable energiesenvironmental benefits, economic growth and job creation. Bremen: Bremer Energie Institut; 2006.

[9] Sastresa E, Usón A, Bribián I, Scarpelleni S. Local impact of renewables on employment: assessment methodology and case study. Renewable and Sustainable Energy Reviews 2010:14:679-90.

[10] Moreno B, López AJ. The effect of renewable energy on employment: the case of Asturias (Spain). Renewable and Sustainable Energy Reviews 2008;12 732-51.

[11] Caldés N, Varela M, Santamaría M, Sáez R. Economic impact of solar thermal electricity deployment in Spain. Energy Policy 2009;37:1628-36.

[12] Alvarez GC, Jara RM, Juliá JRR, Bielsa JIG. Study of the effects on employment of public aid to renewable energy sources, VII. Procesos De Mercado; 2010 [Primavera, Last accessed 21st March 2012] <http://www.juandemariana. org/pdf/090327-employment-public-aid-renewable.pdf $\rangle$.

[13] Global insight, current and potential green jobs in the U.S. economy. Prepared for the United States Conference of Mayors and the Mayors Climate Protection Center; 2008. Last accessed 20th March 2012, 〈http://www. usmayors.org/pressreleases/uploads/greenjobsreport.pdf $>$.

[14] Management Information Services Inc. Estimating the jobs impacts of tackling climate change. Prepared for the American Solar Energy Society; 2009. Last accessed 20th March 2012, 〈http://www.misi-net.com/publica tions/ASES-TCC09.pdf $>$.

[15] Wei M, Patadia S, Kammen DM. Putting renewable and energy efficiency to work: how many jobs can the clean energy industry generate in the US? Energy Policy 2010;38:919-31.

[16] Michaels R, Murphy RP. Green jobs: Fact or Fiction? Washington, DC Institute for Energy Research; 2009 [Last accessed 21st March 2012] $\langle$ http://www.instituteforenergyresearch.org/green-jobs-fact-or-fiction/ $\rangle$.

[17] Lesser J. Renewable energy and the fallacy of 'green' jobs. The Electricity Journal 2010;7:45-53.

[18] DG Energy and Transport, the impact of renewable energy policy on economic growth and employment in the European Union. European Commission; 2009. Last accessed 21st March 2012, 〈http://ec.europa.eu/ energy/renewables/studies/doc/renewables/2009_employ_res_summary.pdf $\rangle$.

[19] Holland D, Cooke C. Sources of structural change in the Washington economy: an input-output perspective. The Annals of Regional Science 1992;26:155-70.
[20] Madlener R, Koller M. Economic and $\mathrm{CO} 2$ mitigation impacts of promoting biomass heating systems: an input-output study for Vorarlberg, Austria. Energy Policy 2007;35:6021-35.

[21] The Solar Foundation, National Solar Jobs Census 2010: a review of the U.S. Solar Workforce; 2010. Last accessed 21st March 2012, <http://thesolarfoun dation.org/research/national-solar-jobs-census $>$.

[22] EPRI. CEC, California renewable technology market and benefits assessment. Palto Alto, CA/Sacramento, CA: Electric Power Research Institute and California Energy Commission; 2001 [EPRI 1001193].

[23] Dalton GJ, Lewis T. Metrics for measuring job creation by renewable energy technologies, using Ireland as a case study. Renewable and Sustainable Energy Reviews 2011;15:2123-33.

[24] EWEA, wind at work: wind energy and job creation in the EU. European Wind Energy Association; 2008. Last accessed 21st March 2012, 〈http://www. ewea.org/fileadmin/ewea_documents/documents/publications/Wind_at_ work_FINAL.pdf $>$.

[25] Gülen G. Defining, measuring and predicting green jobs. Copenhagen Consensus Center; 2011 [Last accessed 21st March 2012] <http://www.copenha genconsensus.com/Default.aspx?ID=1542 $>$.

[26] Huntington $H$. Creating jobs with 'Green' power sources, 17. SUSAEE Dialogue; 2009 [Last accessed 21st March 2012]<http://emf.stanford.edu/ files/pubs/22522/OP64.pdf $>$.

[27] Kammen DM, Kapadia K, Fripp M. Putting renewables to work: How many jobs can the clean energy industry generate? RAEL Report, University of California, Berkeley; 2004.

[28] Metcalf GE. Federal Tax Policy Towards Energy. National Bureau of Economic Research, Working Paper 12568; October 2006.

[29] EIA (Energy Information Administration), Annual Energy Outlook 2011. DOE/ EIA-0383(2010); 2010.

[30] Hughes G. The 'myth' of green jobs. The Global Warming Policy Foundation Report 3, London; 2011. Last accessed 21st March 2012, 〈http://thegwpf.org/ images/stories/gwpf-reports/hughes-green_jobs.pdf $\rangle$.

[31] Bowen A. 'Green' growth, 'green' jobs and labour markets. Policy Research Working Paper 5990, World Bank; 2012. Last accessed 21st March 2012, <http://www-wds.worldbank.org/external/default/WDSContentServer/WDSP/ IB/2012/03/07/000158349_20120307084323/Rendered/PDF/WPS5990.pdf $\rangle$.

[32] del Rio P, Burguillo M. Assessing the impact of renewable energy deployment on local sustainability: towards a theoretical framework. Renewable and Sustainable Energy Reviews 2008;12:1325-44.

[33] Erneuerbare Energien BMU. Arbeitsmarkteffekte. Berlin: Federal Ministry for the Environment, Nature Conservation, and Nuclear Safety; 2006.

[34] European Commission, Communication from the Commission to the European Parliament and the Council-Renewable Energy: progressing towards the 2020 target, $\operatorname{COM}(2011) 31$ final. Brussels; 2011.

[35] Navigant Consulting, jobs impact of a national renewable electricity standard; 2010. Last accessed 20th March 2012, 〈http://ieca-us.com/documents/ RESAllianceNavigantJobsStudy.pdf $>$.

[36] Romero SR, Santos AC, Gil MAC. EU plans for renewable energy: an application to the Spanish case. Renewable Energy 2012;43:322-30.

[37] Knigge M, Kranz N, Klasing A, Görlach B. Job creation potential of clean technologies: study for the European Parliament. Berlin: Institute for International and Environmental Policy; 2004 [Last accessed 20th March 2012 $\langle$ http://ecologic.eu/download/projekte/1800-1849/1848/1848_study.pdf $\rangle$. 